\title{
Antenatal Dexamethasone for Early Preterm Birth in Low-Resource Countries
}

\author{
The WHO ACTION Trials Collaborators
}

ABSTRACT

The members of the writing committee assume responsibility for the overall content and integrity of this article. The full names, academic degrees, and affiliations of the members of the writing committee are listed in the Appendix. Ad dress reprint requests to $\mathrm{Dr}$. Oladapo at the United Nations Development Program-United Nations Population FundUnited Nations Children's Fund-World Health Organization-World Bank Special Program of Research, Development, and Research Training in Human Reproduction, Department of Sexual and Reproductive Health and Research, World Health Organization, 20 Ave. Appia, Geneva, Switzerland, or at oladapoo@who .int; or to Dr. Bahl at the Department of Maternal, Newborn, Child, Adolescent Health and Ageing, World Health Organization, 20 Ave. Appia, Geneva, Switzerland, or atbahlr@who.int.

This article was published on October 23, 2020, at NEJM.org.

This is the New England Journal of Medicine version of record, which includes all Journal editing and enhancements. The Author Final Manuscript, which is the author's version after external peer review and before publication in the Journal, is available under a CC BY license at PMC7660991.

N Engl J Med 2020;383:2514-25. DOI: 10.1056/NEJMoa2022398

Copyright (๑) 2020 Massachusetts Medical Society.

\section{BACKGROUND}

The safety and efficacy of antenatal glucocorticoids in women in low-resource countries who are at risk for preterm birth are uncertain.

\section{METHODS}

We conducted a multicountry, randomized trial involving pregnant women between 26 weeks 0 days and 33 weeks 6 days of gestation who were at risk for preterm birth. The participants were assigned to intramuscular dexamethasone or identical placebo. The primary outcomes were neonatal death alone, stillbirth or neonatal death, and possible maternal bacterial infection; neonatal death alone and stillbirth or neonatal death were evaluated with superiority analyses, and possible maternal bacterial infection was evaluated with a noninferiority analysis with the use of a prespecified margin of 1.25 on the relative scale.

\section{RESULTS}

A total of 2852 women (and their 3070 fetuses) from 29 secondary- and tertiarylevel hospitals across Bangladesh, India, Kenya, Nigeria, and Pakistan underwent randomization. The trial was stopped for benefit at the second interim analysis. Neonatal death occurred in 278 of 1417 infants (19.6\%) in the dexamethasone group and in 331 of 1406 infants (23.5\%) in the placebo group (relative risk, 0.84; $95 \%$ confidence interval [CI], 0.72 to $0.97 ; \mathrm{P}=0.03$ ). Stillbirth or neonatal death occurred in 393 of 1532 fetuses and infants (25.7\%) and in 444 of 1519 fetuses and infants (29.2\%), respectively (relative risk, 0.88 ; $95 \% \mathrm{CI}, 0.78$ to $0.99 ; \mathrm{P}=0.04$ ); the incidence of possible maternal bacterial infection was $4.8 \%$ and $6.3 \%$, respectively (relative risk, 0.76 ; $95 \%$ CI, 0.56 to 1.03 ). There was no significant betweengroup difference in the incidence of adverse events.

\section{CONCLUSIONS}

Among women in low-resource countries who were at risk for early preterm birth, the use of dexamethasone resulted in significantly lower risks of neonatal death alone and stillbirth or neonatal death than the use of placebo, without an increase in the incidence of possible maternal bacterial infection. (Funded by the Bill and Melinda Gates Foundation and the World Health Organization; Australian and New Zealand Clinical Trials Registry number, ACTRN12617000476336; Clinical Trials Registry-India number, CTRI/2017/04/008326.) 
P RETERM BIRTH IS A LEADING CAUSE OF death in infants and children younger than 5 years of age globally. ${ }^{1}$ Infants born preterm are also at increased risk for a wide range of short-term and long-term respiratory, infectious, metabolic, and neurologic conditions, with higher risks among those born during the early preterm period. ${ }^{2,3}$

On the basis of trials conducted largely in high-resource countries, antenatal glucocorticoids have long been promoted as the key intervention for reducing preterm infant mortality and morbidity. 4,5 However, the generalizability of this evidence to low-resource settings was called into question in 2015, when a large population-based trial conducted in six low-resource countries showed that efforts to scale up the use of antenatal glucocorticoids could lead to harm. ${ }^{6}$ In that trial, scaling up of glucocorticoids did not reduce mortality among infants who were below the fifth percentile for birth weight (a proxy for preterm birth) and unexpectedly was associated with an increase in the incidence of neonatal death, stillbirth, and suspected maternal infection in the population overall. These findings reopened the debate about the safety and efficacy of antenatal glucocorticoids in low-resource countries. ${ }^{7,8}$

Because of these considerations, in 2015 the World Health Organization (WHO) recommended that antenatal glucocorticoids should be used only under certain conditions, including the accurate assessment of gestational age, imminent preterm birth, the absence of maternal infection, and adequate care for childbirth and preterm newborns. ' The guideline panel and an expert panel that was subsequently convened by the WHO identified the conduct of efficacy trials in hospitals in low-resource countries as a research priority in order to resolve this controversy and guide clinicians and policymakers on the use of antenatal glucocorticoids. ${ }^{7,8}$ We conducted the WHO ACTION-I (Antenatal Corticosteroids for Improving Outcomes in Preterm Newborns) trial, a randomized trial to assess the safety and efficacy of dexamethasone in women in hospitals in low-resource countries who were at risk for early preterm birth.

\section{METHODS}

TRIAL DESIGN AND OVERSIGHT

We designed a multicountry, multicenter, parallelgroup, double-blind, individually randomized, pla- cebo-controlled trial to compare intramuscular dexamethasone with identical placebo in women at risk for imminent preterm birth. We conducted the trial at 29 secondary- and tertiary-level hospitals across six trial sites in Bangladesh, India, Kenya, Nigeria, and Pakistan. The trial protocol, which has been published previously, ${ }^{10}$ is available with the full text of this article at NEJM.org. It was approved by the relevant ethics committees and regulatory agencies in each country and by the WHO Ethics Review Committee. WHO was the trial sponsor. A steering group comprising a trial coordinating unit, principal investigators, and technical advisors provided trial oversight.

Fresenius Kabi-Labesfal (Portugal) produced dexamethasone sodium phosphate and identical placebo, which were packaged and shipped to the trial sites by Ivers-Lee Clinical Supplies Management (Switzerland). Fresenius Kabi-Labesfal had no role in the trial design, the collection, analysis, and interpretation of the data, the writing of the manuscript, or the decision to submit the manuscript for publication. The first, second, third, and seventh members of the writing committee vouch for the accuracy and completeness of the data and for the fidelity of the trial to the protocol.

\section{TRIAL SETTING}

The trial hospitals were selected through a standardized assessment of maternal and newborn health care services (Table S1 in the Supplementary Appendix, available at NEJM.org) to ensure that the WHO criteria for antenatal glucocorticoid treatment could be reasonably met. ${ }^{8,9}$ To make the trial procedures consistent and to ensure that the trial participants received at least the minimum quality of care, ultrasonographic systems (Philips HD5, the Netherlands), continuous positive airway pressure (CPAP) machines (DiaMedica UK, United Kingdom), pulse oximeters (Masimo International, Switzerland), and glucometers were procured for all the hospitals. Standardized training was provided to all research and clinical staff.

\section{SCREENING AND RECRUITMENT}

Pregnant women who had confirmed live fetuses between 26 weeks 0 days and 33 weeks 6 days of gestation and who were at risk for preterm birth were eligible for inclusion. The inclusion criteria were planned or expected birth in the next 48 hours (either provider-initiated preterm birth or 
after preterm, prelabor rupture of membranes or spontaneous labor). Gestational age was determined by the earliest ultrasonographic examination or an ultrasonographic examination performed at admission. Women were excluded if they had clinical signs of severe infection, major congenital fetal anomalies, concurrent or recent (within the previous 2 weeks) use of systemic glucocorticoids, or a contraindication to glucocorticoids or if they were participating in another trial. Written informed consent was obtained from all the participants before randomization.

\section{RANDOMIZATION AND TRIAL REGIMENS}

The participants were randomly assigned in a 1:1 ratio to a course of intramuscular injections of either $6 \mathrm{mg}$ of dexamethasone or identical placebo administered every 12 hours, for a maximum of four doses, or until hospital discharge or birth. The women were eligible for a repeat course if they had not given birth after 7 completed days but still met the inclusion criteria. The repeat course was identical to the first course and the same as the initial assignment.

Site-stratified individual randomization with balanced permuted blocks of 10 were used. The computer-generated randomization sequence was prepared centrally at the WHO. All the sites received serially numbered identical packs containing ampules of $4 \mathrm{mg}$ per milliliter of dexamethasone or placebo for two full courses. The trial participants, care providers, and investigators were unaware of the trial-group assignments.

The participants received either dexamethasone or placebo immediately after randomization. Clinical care was provided according to local guidelines. Follow-up of the fetuses was conducted until 28 days after birth or until death (stillbirth or neonatal death), whichever came first, and follow-up of the women was conducted until 28 days after they gave birth or until death, whichever came first. Trained research staff collected data during the hospital admission or admissions and during community-level visits.

\section{TRIAL OUTCOMES}

The three primary outcomes were neonatal death (death of a live-born infant within 28 completed days of life), stillbirth or neonatal death, and a composite of possible maternal bacterial infection, defined as maternal fever (temperature $\geq 38^{\circ} \mathrm{C}$ ) or clinically suspected or confirmed infection for which therapeutic antibiotics were used. The secondary outcomes were maternal and newborn mortality and morbidity as well as process-of-care outcomes (a list and definitions of these outcomes are provided in the Statistical Methods section in the Supplementary Appendix).

All trial-related information was stored securely at the trial sites. Data were double-entered into a Web-based data-management platform and centrally managed by Centro Rosarino de Estudios Perinatales (Argentina).

\section{STATISTICAL ANALYSIS}

We estimated that 6018 women would have to be recruited to detect a decrease in the risk of neonatal death of $15.00 \%$ or more, from $25.00 \%$ to $21.25 \%$, in a two-sided $5 \%$ significance test with $90 \%$ power and $10 \%$ loss to follow-up. The estimated sample size would provide more than $80 \%$ power at the $2.5 \%$ significance level to detect whether dexamethasone is noninferior to placebo for maternal infection, within a noninferiority margin of 1.25 on the relative scale. The noninferiority margin was based on the consideration that a maximum increase of $25 \%$ over a $10 \%$ baseline incidence of maternal bacterial infection could be accepted for a fetal or infant mortality benefit.

For the primary outcomes, intention-to-treat analyses were to be performed. We hypothesized that the use of dexamethasone would result in a decrease in the risk of neonatal death and stillbirth or neonatal death without increasing the risk of maternal infection. Therefore, we applied a superiority hypothesis to neonatal death and stillbirth or neonatal death, and we applied a noninferiority hypothesis to maternal infection. Analyses were first performed on all available data, and sensitivity analyses were then performed with the use of multiple imputation ${ }^{11}$ to judge the effect of missing data. Analyses of primary outcomes were corrected for multiplicity with the false-discovery-rate approach. ${ }^{12}$ The dexamethasone group was compared with the placebo group for the primary outcomes with the use of relative risks with $95 \%$ confidence intervals, according to a logistic model with a binomial distribution and a log link to obtain relative risks. The stratifying variable - trial site 
- was included in the model, as well as a clustering feature for multiple births for neonatal outcomes. For continuous variables, means and standard deviations or medians and interquartile ranges according to group were reported. The trial groups were compared with mean or median differences and 95\% confidence intervals according to a general linear model that included trial site as the stratifying variable. Separate models were fitted for each of the primary and secondary outcomes.

The primary outcomes were analyzed in prespecified subgroups (see the Statistical Methods section in the Supplementary Appendix). The results for all secondary outcomes and subgroup analyses are presented as point estimates and $95 \%$ confidence intervals. No correction was made for multiplicity, and the width of the confidence intervals should not be used to infer treatment effects. All the models were fitted with the use of SAS software, version 9.4 (SAS Institute).

Three interim analyses by the data and safety monitoring board were planned. The board members were to inform the steering group chair if, in their view, there was proof beyond a doubt that dexamethasone was indicated or contraindicated on the basis of statistical considerations (using the Haybittle-Peto stopping rule ${ }^{13}$ for the primary outcomes for fetuses and infants) or clinical considerations, practical issues, or new external information. After the second interim analysis involving 2304 women and 2536 fetuses and infants, with complete follow-up of primary outcomes, the data and safety monitoring board decided to unblind the trial and recommended that the trial be stopped for fetus and infant mortality benefits and strong evidence of a graded dose-response effect, in the context of existing evidence of benefits of antenatal glucocorticoids. ${ }^{4}$ Recruitment was stopped across all sites on November 21, 2019, and all ethics committees and regulatory authorities were informed. The funders had no role in the decision to stop the trial.

\section{RESULTS}

PARTICIPANT CHARACTERISTICS

From December 2017 through November 2019, of the 7008 women who were screened for eligibility, 2852 underwent randomization (1429 to the dexamethasone group and 1423 to the placebo group) (Fig. 1). The most common reason for ineligibility was that birth was not planned or expected in the next 48 hours. A total of $90.0 \%$ of the infants in the dexamethasone group and $90.8 \%$ of those in the placebo group were born before 37 weeks. More than $99.0 \%$ of the women who underwent randomization and their infants completed follow-up. The characteristics of the dexamethasone and placebo groups were similar at trial entry (Table 1 and Table S2).

\section{ADHERENCE TO ASSIGNED TRIAL REGIMEN}

All the women except 1 received at least one dose of dexamethasone or placebo (Fig. 1). A total of 815 of 1429 women $(57.0 \%)$ in the dexamethasone group and 756 of 1423 women (53.1\%) in the placebo group received all four doses in the first course. The repeat course was administered to 61 women in the dexamethasone group and 74 women in the placebo group, of whom 46 and 47 women, respectively, received four doses. The most common reason that a scheduled dose was not administered was the occurrence of birth between the administration of doses.

\section{PRIMARY OUTCOMES}

There were 278 neonatal deaths among 1417 liveborn infants in the dexamethasone group (19.6\%) and 331 neonatal deaths among 1406 live-born infants in the placebo group (23.5\%) (relative risk, $0.84 ; 95 \%$ confidence interval [CI], 0.72 to 0.97; $\mathrm{P}=0.03$ ) (Table 2). We determined that 25 women would need to be treated with dexamethasone to prevent 1 neonatal death (95\% CI, 14 to 110). The incidence of stillbirth or neonatal death was also significantly lower in the dexamethasone group than in the placebo group $(25.7 \%$ vs. $29.2 \%$; relative risk, 0.88 ; $95 \% \mathrm{CI}, 0.78$ to 0.99 ; $\mathrm{P}=0.04)$.

Possible maternal bacterial infection occurred in 68 of 1416 women $(4.8 \%)$ in the dexamethasone group and in 89 of 1412 women (6.3\%) in the placebo group (relative risk, 0.76 ; $95 \% \mathrm{CI}$, 0.56 to $1.03 ; \mathrm{P}=0.002$ for noninferiority); this result was consistent with noninferiority at the prespecified margin of 1.25 (Table 2). In the perprotocol population, possible maternal bacterial infection occurred in 63 of 1393 women (4.5\%) in the dexamethasone group and in 89 of 1385 


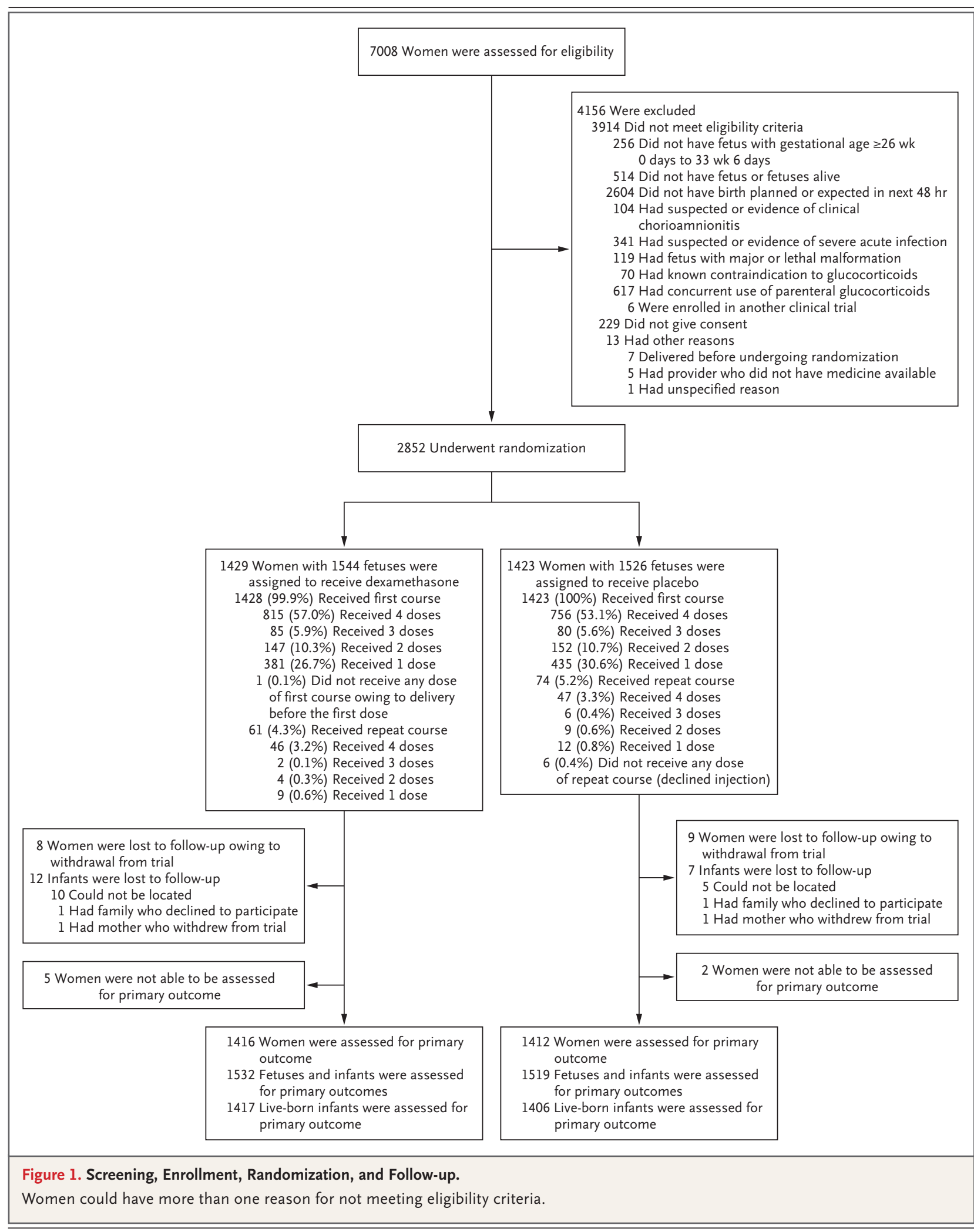




\begin{tabular}{|c|c|c|}
\hline Characteristic & $\begin{array}{l}\text { Dexamethasone } \\
\qquad(\mathrm{N}=1429)\end{array}$ & $\begin{array}{l}\text { Placebo } \\
(\mathrm{N}=1423)\end{array}$ \\
\hline \multicolumn{3}{|c|}{ Clinical assessment of imminent preterm birth at trial entry — no. (\%) } \\
\hline Spontaneously initiated preterm birth & $874(61.2)$ & $858(60.3)$ \\
\hline Preterm prelabor rupture of membranes & $455(31.8)$ & $388(27.3)$ \\
\hline Spontaneous preterm labor & $419(29.3)$ & $470(33.0)$ \\
\hline Provider-initiated preterm birth & $555(38.8)$ & $565(39.7)$ \\
\hline Gestational age at trial entry — wk & $30.8 \pm 2.0$ & $30.7 \pm 2.0$ \\
\hline Maternal age $-\mathrm{yr}$ & $27.5 \pm 5.8$ & $27.5 \pm 5.9$ \\
\hline \multicolumn{3}{|l|}{ Fetuses in the current pregnancy — no. (\%) } \\
\hline Single & $1295(90.6)$ & $1290(90.7)$ \\
\hline Twin & $125(8.7)$ & $129(9.1)$ \\
\hline Higher-order multiples & $9(0.6)$ & $4(0.3)$ \\
\hline Nulliparous women — no. (\%) & $529(37.0)$ & $549(38.6)$ \\
\hline History of preterm birth — no. (\%)† & $177(12.4)$ & $188(13.2)$ \\
\hline \multicolumn{3}{|l|}{ Obstetrical condition present - no. (\%) } \\
\hline Gestational diabetes & $22(1.5)$ & $15(1.1)$ \\
\hline Preeclampsia or eclampsia & $275(19.2)$ & $326(22.9)$ \\
\hline Gestational hypertension $\mathbb{S}$ & $75(5.2)$ & $68(4.8)$ \\
\hline Known or suspected oligohydramnios & $336(23.5)$ & $310(21.8)$ \\
\hline Known or suspected polyhydramnios & $19(1.3)$ & $30(2.1)$ \\
\hline Known or suspected intrauterine growth restriction & $94(6.6)$ & $95(6.7)$ \\
\hline Abruptio placentae & $49(3.4)$ & $40(2.8)$ \\
\hline Placenta previa & $115(8.0)$ & $110(7.7)$ \\
\hline Other obstetrical hemorrhage & $66(4.6)$ & $42(3.0)$ \\
\hline No obstetrical condition & $616(43.1)$ & $592(41.6)$ \\
\hline \multicolumn{3}{|l|}{ Medication administered before randomization — no. (\%) } \\
\hline Tocolytic agent & $251(17.6)$ & $267(18.8)$ \\
\hline Magnesium sulfate for neuroprotection & 141 (9.9) & 179 (12.6) \\
\hline
\end{tabular}

women $(6.4 \%)$ in the placebo group (relative risk, $0.70 ; 95 \%$ CI, 0.51 to 0.96); this result was also consistent with noninferiority. Multiple imputation for missing values ${ }^{11}$ yielded identical results for all the primary outcomes (Table S3).

The results according to the prespecified subgroups are shown in Figure 2 and Figure S1. Analyses of neonatal death, according to the time from the first dose of dexamethasone or placebo to birth, stratified according to gestational age, suggest greater benefit with increasing time from the first dose to birth and increasing gestational age at the first dose (from 26 to 32 weeks) (Fig. S2). In a post hoc analysis of the causes of neonatal death, the frequency of neonatal death caused by respiratory distress syndrome was lower in the dexamethasone group than in the placebo group (Table S4). 


\begin{tabular}{|c|c|c|c|c|}
\hline Outcome & Dexamethasone & Placebo & $\begin{array}{l}\text { Relative Risk } \\
(95 \% \mathrm{CI}) * *\end{array}$ & P Value' \\
\hline \multicolumn{5}{|c|}{ no./total no. (\%) } \\
\hline Neonatal death & 278/1417 (19.6) & $331 / 1406(23.5)$ & $0.84(0.72-0.97)$ & 0.03 \\
\hline Stillbirth or neonatal death & $393 / 1532(25.7)$ & $444 / 1519(29.2)$ & $0.88(0.78-0.99)$ & 0.04 \\
\hline $\begin{array}{l}\text { Possible maternal bacterial } \\
\text { infectiont }\end{array}$ & $68 / 1416(4.8)$ & $89 / 1412(6.3)$ & $0.76(0.56-1.03)$ & $0.002 \sqrt{ }$ \\
\hline
\end{tabular}

* Relative risks and $95 \%$ confidence intervals, calculated from modeling, were adjusted for trial sites and accounted for clustering due to multiple births.

$\uparrow \mathrm{P}$ values were adjusted for multiplicity for the three primary outcomes with the use of the false-discovery-rate approach. Possible maternal bacterial infection was defined as the occurrence of fever (temperature $\geq 38^{\circ} \mathrm{C}$ ) or clinically suspected or confirmed infection for which therapeutic antibiotics were used. Suspected or confirmed infection included obstetrical infection (chorioamnionitis, postpartum endometritis, or wound infection) or nonobstetrical infection (respiratory tract infection [pneumonia, pharyngitis, sinusitis, or a similar infection], urinary tract infection [excluding pyelonephritis], pyelonephritis, acute cholecystitis, or other system infection) captured during hospital admission or admissions only.

$\int$ This $\mathrm{P}$ value was calculated for noninferiority.

\section{SECONDARY NEONATAL OUTCOMES}

The results with respect to early neonatal death, severe respiratory distress at 24 hours after birth, neonatal hypoglycemia at 6 hours after birth, major resuscitation at birth, the use of CPAP, and the duration of oxygen therapy provide support for the primary findings. Other secondary and process-of-care outcomes were similar in the dexamethasone and placebo groups (Table 3 and Table S5).

\section{SECONDARY MATERNAL OUTCOMES}

The secondary maternal outcomes were similar in the dexamethasone and placebo groups (Table 3). Five women died in the dexamethasone group, and four women died in the placebo group.

\section{ADVERSE EVENTS}

Prespecified maternal and neonatal outcomes were excluded from the reporting of serious adverse events. There was no significant betweengroup difference in the incidence of serious adverse events, which occurred in $1.1 \%$ of the women in both groups (Table S6). No serious adverse events were reported in the neonates.

\section{DISCUSSION}

In this hospital-based randomized trial conducted in low-resource countries, we found that the administration of dexamethasone to women who were at risk for early preterm birth reduced the incidences of neonatal death and stillbirth or neonatal death without increasing the incidence of maternal bacterial infection. Dexamethasone had no effect on stillbirth, but the findings for several secondary outcomes, including early neonatal death, severe respiratory distress, and the use of major neonatal resuscitation and CPAP were consistent with the overall results for neonatal deaths by 28 days. These clinical benefits were observed even though $45 \%$ of the participants received fewer than four doses of their assigned medication.

Our findings are generally consistent with the results of a meta-analysis of 22 trials that were mostly conducted in high-resource settings. That meta-analysis showed a substantial decrease in the incidence of neonatal death among infants of women who received glucocorticoids. ${ }^{4}$ Previous efforts to increase the low use of antenatal glucocorticoids in women at risk for preterm birth in low-resource countries ${ }^{14}$ were challenged by the results of the Antenatal Corticosteroids Trial (ACT). ${ }^{6,15}$ ACT was a clusterrandomized trial of an implementation strategy that included provider training and tools to identify women who were eligible to receive dexamethasone at all levels of care, including primary health care and care at the community level.

In contrast to ACT, which selected women for treatment on the basis of their last menstrual period or measurement of uterine height and included clinical settings where resources for neonatal care were inadequate, the hospitals in our trial selected patients for whom treatment 


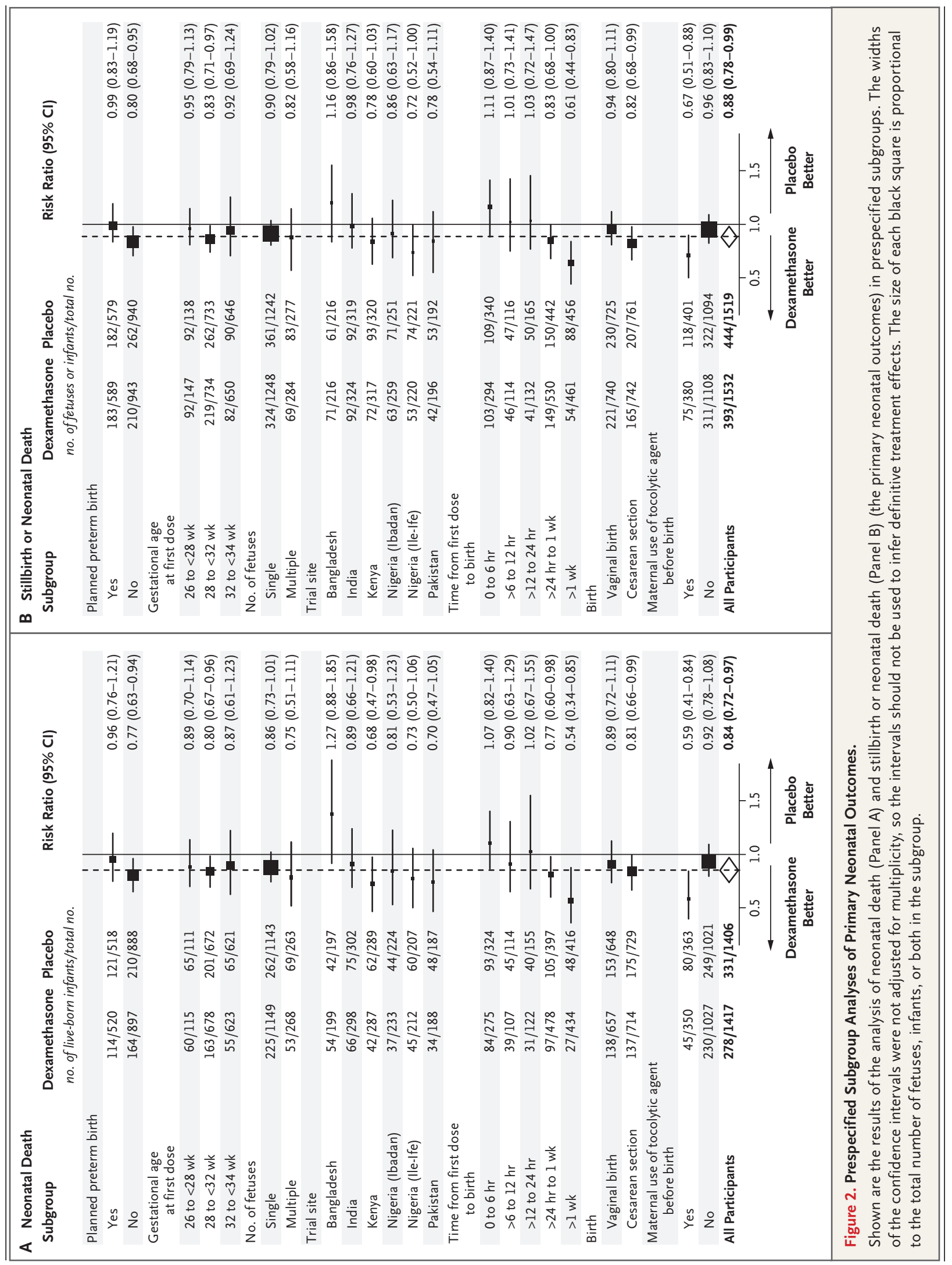




\begin{tabular}{|c|c|c|c|}
\hline \multirow[t]{2}{*}{ Outcome } & Dexamethasone & Placebo & $\begin{array}{l}\text { Relative Risk } \\
(95 \% \mathrm{Cl}) \grave{\dagger}\end{array}$ \\
\hline & \multicolumn{2}{|c|}{ no./total no. (\%) } & \\
\hline \multicolumn{4}{|l|}{ Neonatal outcome } \\
\hline Stillbirth & $115 / 1544(7.4)$ & $113 / 1526(7.4)$ & $1.00(0.78-1.30)$ \\
\hline Early death: $\leq 7$ days after birth & 218/1417 (15.4) & $268 / 1406(19.1)$ & $0.81(0.68-0.96)$ \\
\hline Severe respiratory distress & $116 / 1245(9.3)$ & $141 / 1223(11.5)$ & $0.81(0.64-1.03)$ \\
\hline At $24 \mathrm{hr}$ after birth & $34 / 1122(3.0)$ & $58 / 1065(5.4)$ & $0.56(0.37-0.85)$ \\
\hline Sepsis & $183 / 1284(14.3)$ & $197 / 1264(15.6)$ & $0.92(0.76-1.11)$ \\
\hline Hypoglycemiał & $301 / 1242(24.2)$ & $328 / 1217(27.0)$ & $0.91(0.80-1.04)$ \\
\hline At $6 \mathrm{hr}$ after birth & $92 / 1224(7.5)$ & $123 / 1194(10.3)$ & $0.73(0.56-0.95)$ \\
\hline At $36 \mathrm{hr}$ after birth & $54 / 1035(5.2)$ & $62 / 999(6.2)$ & $0.85(0.60-1.21)$ \\
\hline Severe intraventricular hemorrhage & $6 / 810(0.7)$ & $3 / 720(0.4)$ & $1.85(0.46-7.42)$ \\
\hline Apgar score $<7$ at 5 min after birth & $276 / 1359(20.3)$ & $293 / 1368(21.4)$ & $0.95(0.82-1.10)$ \\
\hline Major resuscitation at birth & $101 / 1382(7.3)$ & $144 / 1383(10.4)$ & $0.70(0.55-0.88)$ \\
\hline Use of oxygen therapy: & $726 / 1429(50.8)$ & $756 / 1413(53.5)$ & $0.95(0.88-1.02)$ \\
\hline Use of CPAP + & $265 / 1429(18.5)$ & $337 / 1413(23.9)$ & $0.78(0.67-0.90)$ \\
\hline Use of mechanical ventilation & $83 / 1284(6.5)$ & $103 / 1264(8.1)$ & $0.79(0.59-1.05)$ \\
\hline $\begin{array}{l}\text { Use of parenteral therapeutic antibiotics } \\
\text { for } \geq 5 \text { days } \rrbracket\end{array}$ & $527 / 1245(42.3)$ & $494 / 1175(42.0)$ & $1.00(0.91-1.10)$ \\
\hline Use of surfactant & $9 / 1284(0.7)$ & $18 / 1264(1.4)$ & $0.49(0.22-1.08)$ \\
\hline Admission to a special care unit & $905 / 1287(70.3)$ & $897 / 1268(70.7)$ & $0.99(0.94-1.04)$ \\
\hline Readmission & $39 / 1429(2.7)$ & $48 / 1413(3.4)$ & $0.81(0.53-1.25)$ \\
\hline \multicolumn{4}{|l|}{ Maternal outcome } \\
\hline Death & $5 / 1429(0.4)$ & $4 / 1423(0.3)$ & $1.23(0.33-4.57)$ \\
\hline Fever & $78 / 1417(5.5)$ & $70 / 1406(5.0)$ & $1.10(0.80-1.50)$ \\
\hline Chorioamnionitis & $17 / 1429(1.2)$ & $18 / 1423(1.3)$ & $0.93(0.48-1.80)$ \\
\hline Endometritis & $5 / 1429(0.4)$ & $3 / 1423(0.2)$ & $1.65(0.39-6.92)$ \\
\hline Wound infection & $8 / 1429(0.6)$ & $15 / 1423(1.1)$ & $0.53(0.22-1.25)$ \\
\hline Nonobstetrical infection & $34 / 1429(2.4)$ & $42 / 1423(3.0)$ & $0.81(0.52-1.26)$ \\
\hline Use of therapeutic antibiotics & $68 / 1427(4.8)$ & $89 / 1422(6.3)$ & $0.76(0.56-1.03)$ \\
\hline Any antibiotic use & $1205 / 1353(89.1)$ & $1216 / 1355$ (89.7) & $1.00(0.97-1.02)$ \\
\hline Postpartum readmission & $14 / 1429(1.0)$ & $13 / 1423(0.9)$ & $1.07(0.50-2.26)$ \\
\hline
\end{tabular}

* CPAP denotes continuous positive airway pressure.

$\uparrow$ The $95 \%$ confidence intervals are not adjusted for multiplicity and should not be used to infer definitive treatment effects.

$¥$ This outcome was measured from the initial postnatal hospitalization until death, discharge, or completed day 7 (whichever came first).

$\int$ This category includes the use of parenteral therapeutic antibiotics in neonates for 5 days or more, even if interrupted, except for the use in those who died before 5 completed days. Referral of live-born infants for treatment was not included because of very few events.

was warranted (through assessment by obstetrical physicians and verification of gestational age by ultrasonographic examination) and provided minimum standards of neonatal care, including access to oxygen and CPAP. In the current trial, $90 \%$ of the infants who were exposed to dexamethasone were born preterm, whereas only $16 \%$ of the infants exposed to dexamethasone in the 
ACT intervention clusters had a birth weight below the fifth percentile. The low incidence of apparent preterm birth among infants exposed to dexamethasone in ACT indicates substantial overtreatment, which may explain at least in part the lack of mortality benefit and overall harm observed. Appropriate selection of participants and the provision of a minimum standard of care appear to be critical in achieving benefits and preventing potential harms from glucocorticoids and should be incorporated into future implementation strategies.

The results of our trial provide reassurance regarding the beneficial effects of glucocorticoids with respect to reducing neonatal mortality in low-resource settings, and they expand the scarce body of evidence from low- and middleincome countries. ${ }^{16-20}$ Although smaller trials conducted in low- and middle-income countries have suggested benefits, most of them were not placebo-controlled trials. ${ }^{17,19,20}$

The use of dexamethasone in our trial did not increase the risk of maternal or neonatal infection; this finding is consistent with those of previous trials conducted in low- and middleincome countries, ${ }^{16-20}$ where the baseline risks of such infections are high. ${ }^{21-23}$ The lack of effect on the overall incidence of neonatal hypoglycemia and the suggestion of a reduced risk of early hypoglycemia with the use of dexamethasone, however, were unexpected. Studies in animals and pharmacokinetic studies have indicated that neonatal hypoglycemia is a potential complication of the use of standard doses of dexamethasone. ${ }^{24}$ Moreover, in the Antenatal Late Preterm Steroids trial, the administration of betamethasone to women with a singleton pregnancy at 34 weeks 0 days to 36 weeks 5 days of gestation who were at risk for preterm birth increased the incidence of neonatal hypoglycemia by $60 \% .^{25}$ The effects of maternal glucocorticoid administration on preterm infants have been inconsistent across studies ${ }^{26,27}$ and may differ in infants with early preterm birth and those with late preterm birth.

The current trial is larger than previous placebo-controlled trials assessing the efficacy and safety of antenatal glucocorticoids in low-resource countries, and we used broad eligibility criteria. We assessed neonatal death according to the standard definition (which was largely unspecified or restricted to in-hospital deaths in previ- ous trials ${ }^{7}$ ), and we carefully selected hospitals that could reasonably meet minimum preconditions for glucocorticoid use. The loss to followup of trial participants and the percentage of participants with missing primary outcome data were very low despite the need for follow-up in the community. The trial was limited by the challenges in standardizing maternal and neonatal care across trial sites and the use of ultrasonographic examination to assess gestational age for a substantial percentage of the participants in the third trimester.

Further study is warranted to determine the most appropriate dosing regimen ${ }^{28,29}$ and the safety and efficacy of administering glucocorticoids in late preterm pregnancy, ${ }^{30}$ particularly in low-resource countries. The observed benefits with respect to neonatal mortality appeared to increase with tocolysis and with the duration of fetal exposure to dexamethasone; the role of tocolytic agents in safely delaying early preterm birth in women who are eligible for the use of antenatal glucocorticoids also merits further investigation.

The use of antenatal dexamethasone that was targeted to women at risk for imminent preterm birth in hospitals with minimum resources for maternal and preterm newborn care resulted in significantly lower risks of neonatal death and stillbirth or neonatal death than did the use of placebo, without any evidence of harm to women or newborns.

Supported by a grant (OPP1136821) from the Bill and Melinda Gates Foundation and by the United Nations Development Program-United Nations Population Fund-United Nations Children's Fund-World Health Organization-World Bank Special Program of Research, Development, and Research Training in Human Reproduction, Department of Sexual and Reproductive Health and Research and the Department of Maternal, Newborn, Child, Adolescent Health and Ageing, World Health Organization, Geneva.

Disclosure forms provided by the authors are available at NEJM.org.

A data sharing statement provided by the authors is available with the full text of this article at NEJM.org.

We thank the women and infants who participated in this trial; the physicians, midwives, pharmacists, data managers, and research assistants who helped conduct the trial in each of the five countries (in Bangladesh, Mohammad A. Mannan, Begum Nasrin, Saima Sultana, Saria Tasnim, Sumia Bari, Murshed A. Chowdhury, Dilip K. Bhowmik, and Jamila K. Chowdhury; in India, Vishwanath L. Machakanur, Shruti S. Andola, Yogesh Kumar S., Umesh C. Charantimath, Avinash Kavi, Saraswati A. Welling, Bhavana B. Lakhkar, Umesh Ramadurg, Maya Padhi, Lucy Das, Madhusmita J. Pradhan, Girija-Shankar G. Mohanty, and Paresh Sahoo; in Kenya, Msuo Omar, Mwanapazia Hassan, Joachim Ogindo, Salome Waweru, and Grace Ochieng; in Nigeria [Ibadan], Bukola Fawole [deceased], Oluwakemi F. Ashubu, 
Olukemi Tongo, Olubunmi O. Busari, Michael A. Okunlola, Olatunji Lawal, Collins Kalu, Francisca N. Ali, Kenneth Nwachukwu, Fatima A. Sallau, Lilian O. Ekwem, Anastasia E. Ajuwan, Folarin B. Jimoh, Felix F. Akindeju, Olugbenga Runsewe, Abimbola O. Oladeji, Olumide Alao, and Madise-wobo Akpoembele; in Nigeria [Ile-Ife], Adebanjo B. Adeyemi, Olusola C. Famurewa, Nosakhare O. Enaruna, Olufunmilayo V. Adebara, Aboyeji A. Peter, and Mokuolu Olugbenga; and in Pakistan, Mubarak Ali, Saleem Laghari, Jamal Anwar, Shazia Memon, Nida Najmi, Shazia Rani, Farrukh Raza, Masawar Hussain, Amjad Hussain, and Imran Ahmed); the members of the data and safety monitoring board (Betty Kirkwood [chair], Jon Deeks [independent statistician], Siddarth Ramji, Elizabeth Bukusi, and Robert Pattinson [who served from 2015-2019], and G. Justus Hofmeyr [who began to serve in 2019]) for their role in monitoring the overall conduct and quality of the trial; Cynthia Pileggi-Castro for trial protocol development; Liana Campodonico and Gabriela Camacho Garcia for data management; Vania A. Nilsson and Luciana Abreu for statistical programming and analysis; Lynn Coppola, Sandhya Maranna, and Devasenathipathy Kandasamy for obstetrical and neonatal ultrasonography training and quality assurance; Adam Devall for preparing the subgroup analysis figures; and Janna Patterson, Jerker Liljestrand, and Hilary Gammill for their technical input and support as program managers for the WHO ACTION Trials Collaboration at the Bill and Melinda Gates Foundation.

\section{APPENDIX}

The members of the writing committee are as follows: Olufemi T. Oladapo, M.D., M.P.H., Joshua P. Vogel, M.B., B.S., Ph.D., Gilda Piaggio, Ph.D., My-Huong Nguyen, M.D., Ph.D., Fernando Althabe, M.D., A. Metin Gülmezoglu, M.D., Ph.D., Rajiv Bahl, M.D., Ph.D., Suman P.N. Rao, M.B., B.S., M.D., D.M., Ayesha De Costa, M.D., Ph.D., Shuchita Gupta, M.B., B.S., M.D., M.P.H., Ph.D., Abdullah H. Baqui, M.B., B.S., M.P.H., Dr.P.H., Rasheda Khanam, M.B., B.S., M.P.H., Ph.D., Mohammod Shahidullah, M.B., B.S., Saleha B. Chowdhury, M.B., B.S., Salahuddin Ahmed, M.B., B.S., Nazma Begum, M.A., Dip.Comp.Sc., Arunangshu D. Roy, M.B., B.S., M.A. Shahed, M.B., B.S., Iffat A. Jaben, M.B., B.S., M.P.H., Farida Yasmin, M.B., B.S., M. Mozibur Rahman, M.B., B.S., Anjuman Ara, M.B., B.S., Soofia Khatoon, M.B., B.S., M.H.P.Ed., Gulshan Ara, M.B., B.S., Shaheen Akter, M.B., B.S., M.D., Nasreen Akhter, M.B., B.S., Probhat R. Dey, M.B., B.S., M.D., M. Abdus Sabur, M.B., B.S., Mohammad T. Azad, M.B., B.S., M.D., Shahana F. Choudhury, M.B., B.S., M.A. Matin, M.B., B.S., Shivaprasad S. Goudar, M.D., Sangappa M. Dhaded, M.D., Mrityunjay C. Metgud, M.D., Yeshita V. Pujar, M.D., Manjunath S. Somannavar, M.D., Sunil S. Vernekar, M.D., Veena R. Herekar, M.D., Shailaja R. Bidri, M.D., Sangamesh S. Mathapati, M.D., Preeti G. Patil, D.N.B., Mallanagouda M. Patil, M.D., Muttappa R. Gudadinni, M.D., Hidaytullah R. Bijapure, M.D., Ashalata A. Mallapur, M.D., Geetanjali M. Katageri, M.S., Sumangala B. Chikkamath, M.D., Bhuvaneshwari C. Yelamali, M.D., Ramesh R. Pol, M.D., Sujata S. Misra, M.D., Leena Das, M.D., Saumya Nanda, M.D., Rashmita B. Nayak, M.D., Bipsa Singh, M.D., Zahida Qureshi, M.B., B.S., Fredrick Were, M.B., Ch.B., Ph.D., Alfred Osoti, M.B., Ch.B., M.P.H., Ph.D., George Gwako, M.B., Ch.B., Ahmed Laving, M.B., Ch.B., John Kinuthia, M.B., Ch.B., M.P.H., Hafsa Mohamed, M.B., Ch.B., Nawal Aliyan, M.B., Ch.B., Adelaide Barassa, M.B., Ch.B., Elizabeth Kibaru, M.B., Ch.B., Margaret Mbuga, M.B., Ch.B., Lydia Thuranira, M.B., Ch.B., Njoroge J. Githua, M.B., Ch.B., Bernadine Lusweti, M.B., Ch.B., Adejumoke I. Ayede, M.B., B.S., Adegoke G. Falade, M.B., B.S., M.D., Olubukola A. Adesina, M.B., B.S., Atinuke M. Agunloye, M.B., B.S., Oluwatosin O. Iyiola, M.B., Ch.B., Wilfred Sanni, B.M., B.Ch., Ifeyinwa K. Ejinkeonye, M.B., B.S., Hadiza A. Idris, M.B., B.S., M.R.H., Chinyere V. Okoli, M.B., B.S., M.P.H., Theresa A. Irinyenikan, M.B., B.S., M.P.H., Omolayo A. Olubosede, M.B., B.S., M.P.H., Olaseinde Bello, M.B., Ch.B., Olufemi M. Omololu, M.B., B.S., Olanike A. Olutekunbi, M.B., B.S., Adesina L. Akintan, M.B., B.S., Olorunfemi O. Owa, M.B., B.S., M.P.A., Rosena O. Oluwafemi, M.B., Ch.B., M.P.H., Ireti P. Eniowo, M.B., B.S., Adetokunbo O. Fabamwo, M.B., B.S., Elizabeth A. Disu, M.B., B.Ch., Joy O. Agbara, M.B., B.S., Ebunoluwa A. Adejuyigbe, M.B., Ch.B., Oluwafemi Kuti, M.B., B.S., Henry C. Anyabolu, M.B., B.S., Ibraheem O. Awowole, M.B., Ch.B., Akintunde O. Fehintola, M.B., B.S., M.P.H., Bankole P. Kuti, M.B., Ch.B., Anthony D. Isah, M.B., B.S., Eyinade K. Olateju, M.B., B.S., Olusanya Abiodun, M.B., Ch.B., Olabisi F. Dedeke, M.B., B.S., M.P.H., Francis B. Akinkunmi, M.B., Ch.B., Lawal Oyeneyin, M.B., B.S., Omotayo Adesiyun, M.B., B.S., Hadijat O. Raji, M.B., B.S., Adedapo B.A. Ande, M.B., Ch.B., M.P.H., Ikechukwu Okonkwo, M.B., B.S., Shabina Ariff, M.B., B.S., Sajid B. Soofi, M.B., B.S., Lumaan Sheikh, M.B., B.S., Saima Zulfiqar, M.B., B.S., Sadia Omer, M.B., B.S., Raheel Sikandar, M.B., B.S., Salma Sheikh, M.B., B.S., Daniel Giordano, B.Sc., Hugo Gamerro, B.Sc., Guillermo Carroli, M.D., Jose Carvalho, B.Sc., M.Sc., Ph.D., James Neilson, M.D., Elizabeth Molyneux, M.B., B.S., Khalid Yunis, M.D., Kidza Mugerwa, M.B., Ch.B., and Harish K. Chellani, M.D.

The affiliations of the members of the writing committee are as follows: World Health Organization, Geneva (O.T.O., J.P.V., G.P., M.-H.N., F.A., A.M.G., R.B., S.P.N.R., A.D.C., S.G.); Johns Hopkins Bloomberg School of Public Health, Baltimore (A.H.B., R.K.); Bangabandhu Sheikh Mujib Medical University (M.S., S.B. Chowdhury), Projahnmo Research Foundation (S. Ahmed, N.B., A.D.R., M.A. Shahed, I.A.J.), Institute of Child and Mother Health (F.Y., M.M.R.), Center for Woman and Child Health (A.A., S.K.), and Enam Medical College and Hospital (G.A., S. Akter), Dhaka, and Sylhet Muhammad Ataul Gani Osmani Medical College Hospital (N. Akhter, P.R.D.), Jalalabad Ragib-Rabeya Medical College Hospital (M.A. Sabur, M.T.A.), and Sylhet Women's Medical College Hospital (S.F.C., M.A.M.), Sylhet — both in Bangladesh; KLE Academy of Higher Education and Research, Jawaharlal Nehru Medical College, Belagavi (S.S.G., S.M.D., M.C.M., Y.V.P., M.S.S., S.S.V., V.R.H.), Shri B.M. Patil Medical College, Vijayapura (S.R.B., S.S. Mathapati, P.G.P., M.M.P., M.R.G., H.R.B.), S. Nijalingappa Medical College, Bagalkot (A.A.M., G.M.K., S.B. Chikkamath, B.C.Y., R.R.P.), Srirama Chandra Bhanja Medical College, Cuttack (S.S. Misra, L.D., S.N., R.B.N., B.S.), and Vardhman Mahavir Medical College and Safdarjung Hospital, New Delhi (H.K.C.) — all in India; University of Nairobi (Z.Q., F.W., A. Osoti, G.G., A.L.) and Kenyatta National Hospital (J.K.), Nairobi, Coast Provincial General Hospital, Mombasa (H.M., N. Aliyan), Nakuru Level 5 Hospital, Nakuru (A.B., E.K.), Kiambu Level 5 Hospital, Kiambu (M.M., L.T.), and Thika Level 5 Hospital, Thika (N.J.G., B.L.) — all in Kenya; the College of Medicine, University of Ibadan, and University College Hospital, Ibadan (A.I.A., A.G.F., O.A.A., A.M.A., O.O.I.), Kubwa General Hospital, Kubwa (W.S., I.K.E.), Nyanya General Hospital, Nyanya (H.A.I., C.V.O.), State Specialist Hospital (T.A.I., O.A. Olubosede, O.B.) and Mother and Child Hospital (A.L.A., O.O.O., R.O.O., I.P.E.), Akure, Lagos Island Maternity Hospital (O.M.O., O.A. Olutekunbi), and Lagos State University Teaching Hospital (A.O. Fabamwo, E.A.D., J.O.A.), Lagos, Obafemi Awolowo University, Ile-Ife (E.A.A., O.K., H.C.A., I.O.A., A.O. Fehintola, B.P.K.), University of Abuja, Abuja (A.D.I., E.K.O.), Sacred Heart Hospital, Abeokuta (O. Abiodun, O.F.D.), Mother and Child Hospital, Ondo (F.B.A., L.O.), University of Ilorin, Ilorin (O. Adesiyun, H.O.R.), and University of Benin, Benin City (A.B.A.A., I.O.) - all in Nigeria; Aga Khan University, Karachi (S. Ariff, S.B.S., L.S.), Sheikh Zayed Medical College and Hospital, Rahim Yar Khan (S.Z., S.O.), and Liaquat University Hospital, Hyderabad (R.S., S.S.) — all in Pakistan; Centro Rosarino de Estudios Perinatales, Rosario, Argentina (D.G., H.G., G.C.); Statistika Consultoria, Campinas, Brazil (J.C.); University of Liverpool, Liverpool, United Kingdom (J.N.); College of Medicine, University of Malawi, Blantyre (E.M.); American University of Beirut, Beirut, Lebanon (K.Y.); and the Makerere University College of Health Sciences, Kampala, Uganda (K.M.). 


\section{REFERENCES}

1. Levels and trends in child mortality 2019: estimates developed by the UN Inter-agency Group for Child Mortality Estimation. New York: United Nations Children's Fund, 2019 (https://www.unicef.org/ reports/levels-and-trends-child-mortality -report-2019).

2. Platt MJ. Outcomes in preterm infants. Public Health 2014;128:399-403.

3. Saigal S, Doyle LW. An overview of mortality and sequelae of preterm birth from infancy to adulthood. Lancet 2008; 371:261-9.

4. Roberts D, Brown J, Medley N, Dalziel SR. Antenatal corticosteroids for acceler ating fetal lung maturation for women at risk of preterm birth. Cochrane Database Syst Rev 2017;3:CD004454.

5. Ballard PL, Ballard RA. Scientific basis and therapeutic regimens for use of antenatal glucocorticoids. Am J Obstet Gynecol 1995;173:254-62.

6. Althabe F, Belizán JM, McClure EM, et al. A population-based, multifaceted strategy to implement antenatal corticosteroid treatment versus standard care for the reduction of neonatal mortality due to preterm birth in low-income and middleincome countries: the ACT cluster-randomised trial. Lancet 2015;385:629-39.

7. Vogel JP, Oladapo OT, Pileggi-Castro C, et al. Antenatal corticosteroids for women at risk of imminent preterm birth in lowresource countries: the case for equipoise and the need for efficacy trials. BMJ Glob Health 2017;2(3):e000398

8. Vogel JP, Oladapo OT, Manu A, Gülmezoglu AM, Bahl R. New WHO recommendations to improve the outcomes of preterm birth. Lancet Glob Health 2015; 3(10):e589-e590.

9. WHO recommendations on interventions to improve preterm birth outcomes. Geneva: World Health Organization, 2015. 10. WHO ACTION Trials Collaborators The World Health Organization ACTION-I (Antenatal CorTicosteroids for Improving Outcomes in preterm Newborns) Trial: a multi-country, multi-centre, two-arm, parallel, double-blind, placebo-controlled, individually randomized trial of antenata corticosteroids for women at risk of imminent birth in the early preterm period in hospitals in low-resource countries. Trials 2019;20:507.

11. Berglund PA. An introduction to multiple imputation of complex sample data using SAS v9.2. Presented at the SAS Global Forum, Seattle, April 11-14, 2010. 12. Benjamini Y, Hochberg Y. Controlling the false discovery rate: a practical and powerful approach to multiple testing. J R Stat Soc B 1995;57:289-300.

13. Peto R, Pike MC, Armitage P, et al. Design and analysis of randomized clinical trials requiring prolonged observation of each patient. I. Introduction and design. Br J Cancer 1976;34:585-612.

14. Vogel JP, Souza JP, Gülmezoglu AM, et al. Use of antenatal corticosteroids and tocolytic drugs in preterm births in 29 countries: an analysis of the WHO Multicountry Survey on Maternal and Newborn Health. Lancet 2014;384:1869-77.

15. Hodgins S. Antenatal corticosteroids: Primum non nocere. Glob Health Sci Pract 2018;6:620-3.

16. Amorim MM, Santos LC, Faúndes A. Corticosteroid therapy for prevention of respiratory distress syndrome in severe preeclampsia. Am J Obstet Gynecol 1999; 180:1283-8

17. Fekih M, Chaieb A, Sboui H, Denguezli W, Hidar S, Khairi H. Value of prenatal corticotherapy in the prevention of hyaline membrane disease in premature infants. Randomized prospective study. Tunis Med 2002;80:260-5. (In French.) 18. Pattinson RC, Makin JD, Funk M, et al. The use of dexamethasone in women with preterm premature rupture of membranes - a multicentre, double-blind, placebocontrolled, randomised trial. S Afr Med J 1999;89:865-70.

19. Qublan HS, Malkawi HY, Hiasat MS, et al. The effect of antenatal corticosteroid therapy on pregnancies complicated by premature rupture of membranes. Clin Exp Obstet Gynecol 2001;28:183-6.

20. Lopez ALV, Rojas R, Rodriguez MV, Sanchez AJ. Use of corticoids in preterm pregnancy with premature rupture of membranes. Rev Colomb Obstet Ginecol 1989;40:147-51.

21. WHO Global Maternal Sepsis Study (GLOSS) Research Group. Frequency and management of maternal infection in health facilities in 52 countries (GLOSS): a 1-week inception cohort study. Lancet Glob Health 2020;8(5):e661-e671.

22. Seale AC, Blencowe $H$, Manu AA, et al. Estimates of possible severe bacterial infection in neonates in sub-Saharan Africa, south Asia, and Latin America for 2012: a systematic review and meta-analysis. Lancet Infect Dis 2014;14:731-41.

23. Thaver D, Zaidi AK. Burden of neonatal infections in developing countries: a review of evidence from communitybased studies. Pediatr Infect Dis J 2009; 28:Suppl:S3-S9.

24. Jobe AH, Milad MA, Peppard T, Jusko WJ. Pharmacokinetics and pharmacodynamics of intramuscular and oral betamethasone and dexamethasone in reproductive age women in India. Clin Trans Sci 2020;13:391-9.

25. Gyamfi-Bannerman C, Thom EA, Blackwell SC, et al. Antenatal betamethasone for women at risk for late preterm delivery. N Engl J Med 2016;374:1311-20.

26. di Pasquo E, Saccone G, Angeli L, et al. Determinants of neonatal hypoglycemia after antenatal administration of corticosteroids (ACS) for lung maturation: data from two referral centers and review of the literature. Early Hum Dev 2020;143: 104984.

27. Kuper SG, Baalbaki SH, Parrish MM, Jauk VC, Tita AT, Harper LM. Association between antenatal corticosteroids and neonatal hypoglycemia in indicated early preterm births. J Matern Fetal Neonatal Med 2018;31:3095-101.

28. Kemp MW, Schmidt AF, Jobe AH. Optimizing antenatal corticosteroid therapy. Semin Fetal Neonatal Med 2019;24:176-81. 29. Kemp MW, Saito M, Usuda $H$, et al. The efficacy of antenatal steroid therapy is dependent on the duration of low-concentration fetal exposure: evidence from a sheep model of pregnancy. Am J Obstet Gynecol 2018;219(3):301.e1-301.e16.

30. Kamath-Rayne BD, Rozance PJ, Goldenberg RL, Jobe AH. Antenatal corticosteroids beyond 34 weeks gestation: What do we do now? Am J Obstet Gynecol 2016; 215:423-30.

Copyright (c) 2020 Massachusetts Medical Society. 